\title{
On the Ludic Character of Literary Allusion
}

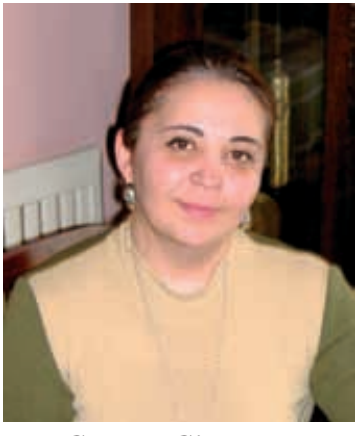

Gayane Girunyan

7 he view that literary allusion is closely associated with the notions of game and playing has long been established, the ludic aspect of alluding being acknowledged by a number of scholars ${ }^{1}$. Indicative of the ludic component enclosed in allusion is the etymology of the word (alludere; lus = play) too. However, the stating of the above is not sufficient unless the nature of such a game is disclosed, in other words, the key concepts by means of which it is defined are presented and the constant characteristics are specified.

To start with, central to literary allusion as a textual phenomenon is the so-called hermeneutical dialogue between text and reader, in which the potential of game is realized due to an interaction between the horizons of text and reader, which Gadamer calls 'fusion of horizons'2, and in which the role of reader's interpretive effort is essential. Moreover, literary allusion provides more complex and at times intricate possibilities for interpretive unfolding as it is not confined to one text only and, using Schaar's vivid description, "layers of infracontexts fan out underneath one another"3. Being a complex sign of double (and at times of multiple) textual reference and having the power of relating texts ${ }^{4}$, literary allusion occurs in the centre of another dialogue: intertextual, which makes the role of powerful reader more meaningful, and therefore, the hermeneutical situation richer. In other words, literary allusion is constituted in and through interpretation and acquires hermeneutical value. The latter, as it will be shown below, is decisive in defining the nature of the game in which the reader is involved.

It can hardly be argued that the expanse of playing and games is immense: it ranges from children's games to intellectual contests, etc. On the other hand, despite the vast variety of forms, this sphere of human activity should have general characteristics, which stand through all the possible manifestations inasmuch as the desire to play and the faculty for creating new play-forms are existentially indispensable to human nature.

That playing is a necessity and, as such, permeates culture is best illustrated by Huizinga, some of whose observations prove helpful in this attempt to define the ludic character of literary allusion. Proceeding from the standpoint that the notion of playing is beyond the polarization of such concepts as truth and falsehood, good and evil, etc., as well as seeing no controversy between playing and the serious, Huizinga considers playing as a self-sufficing and temporary activity whose aim is playing itself ${ }^{5}$. On this 
basis Huizinga formulates a group of characteristic features, which he considers as definitive in revealing the essence of playing $[5 ; 20-29]$. Some of these, I intend to show, apply to literary allusion.

Before the features relating the two notions (game/playing and allusion/alluding) are presented, two points need to be clarified. The first concerns interpreting the author's intention. Acknowledging the factors of the author's subjectivity (personality, world outlook, etc.), as well as his part in initiating the game (as if calling the powerful reader to respond to his challenge), I adhere to the principle of hermeveutical dialogue in which one participant is the text and the other is the reader. As for the author's intention, its manifestation is in and within the world of the text: its language and aesthetic integrity. The second concerns the coverage and correlation of the two notions (game - allusion). Namely, when saying that allusion has a ludic component, i.e. it is a sort of game, I have in mind not only the concrete linguistic sign, but also the fact of alluding and finally, the interpretation of the textual fact in question.

Thus, from this reader-oriented standpoint, the following features come to the fore: recurrence (1), interpretive space (2), regular structure (3), aesthetic impact (4), and tension attended by intellectual and aesthetic appreciation (5).

That recurrence is characteristic of allusion and its possible unfolding in interpretation may be seen in the following perspective. Firstly, the same literary source or literary fact can be alluded to in various contexts. For example. Prufrock in T.S. Eliol's poem "The Love Song of J. Alfred Prufrock" and Eustace in H. James's story "Master Eustace" deny any similarity with Hamlet, and in both cases the reader is referred to the same source. Such extumples are numerous. Secondly, the same alluding text is assimilated in a multitude of interpretations, or hermeneutical dialogues, and by different readers, therefore, the game of interpreting is played over and over. And finally, one and the same understanding consciousness can at any time reflect back on the alluding text, and it is natural to expect that the space in which allusion is constituted the horizon of understanding - does not remain unchanged. Typically, when reading the text newly, one discovers new depths and has new associations and the horizon of understanding formed due to the fusion of the individual horizons of text and reader, and hence the meaning created within the horizon, are subject to dialectical and dynamic changes.

The third feature characterizing allusion and its interpretation (or understanding) is regular structure conditioned by the relations in which literary allusion is rooted and in the centre of which are the notions context and knowledge. Of these the first allows to view allusion in the interdependence of part and whole, which in hermeneutical tradition is known by the metaphor of hermenentical circle. The second, knowledge - and more precisely, backgrom (prior) knowledge as the precondition of any interpretation of literary allusion - sets allusion in two more circles: knowledge - cognition and cognition - understanding. The three pairs taken separately as fundamental relations form endless circles in which one component is the prerequisite for the other, that is, one cannot be 
viewed independent of the other. In such circular relations the whole is constituted in its parts, and any part is understood in the context of the whole; knowledge underlies any further extension of cognition, at the same time being the result of a cognitive process. Similar is the interrelation between cognition and understanding, especially if we remember that the starting point for the meaning-creating reader of allusion is the recognition of 'foreign' elements in the text.

Obviously, these are relations of general characler each of which, figuratively speaking, encircles literary allusion. On the other hand, in the spiral of understanding they are not isolated, and if we model the understanding of literary allusion as a series of consecutive reflections, a hierarchy of levels emerges, the last one of which corresponds to that of understanding the whole. The concept and level of whole in this case is comparable to the formation of a complex contextual structure which cannot be restricted to the individual texts (alluding and alluded), but is an intertextual 'entity" which belongs to the reader's horizon of understanding. It is at this level that the reader correlates the two contexts and that any interpretation may be more or less complete.

Apart from the concepts horizon of understanding, hermeneutical circles, context and knowledge, another one - horizon of question - proves useful in developing the model of understanding of literary allusion.

According to Gadamer, the right/correct question and its horizon are definitive in processing a hermeneutical situation $[2 ; 398]$ and there is a closest relation between such a question and knowledge, the first being the direct way to the second $[2 ; 428]$. Hence, to understand a text means to understand the question, forming the horizon of question $[2 ; 435]$.

Thus, with the effective question as a trigger activating the process of understanding - a most important factor in the formation of the horizon of underslanding and a structure due to which the three circles are collectively established - we get a sequence of questions which reveal levels in understanding, with prior knowledge conducing to preunderstanding and knowledge to understanding.

The succession of steps and the dynamism of modifications (prior knowledge > knowledge; pre-understanding > understanding) suggest that the component of process should be included in the model too. It is obvious that the notion "process of understanding' is to a certain extent conventional as it is not restricted to rigid time limits. On the other hand, if we intend to correlate it with real time, one effective way is to introduce the component of real process of reading, the starting point of which coincides with that of understanding.

For this purpose more appropriate seem prose pieces, which imply certain duration due to volune and the real time of reading which may be regarded as outlining, but not limiting, the process of understanding. With this prerequisite, the model displays the tendency from part to whole. However, when the circles have been established (i.e. the reader has 'embraced' the whole) the interdependence and interplay of the components can be considered and reconsidered from any point or angle. 


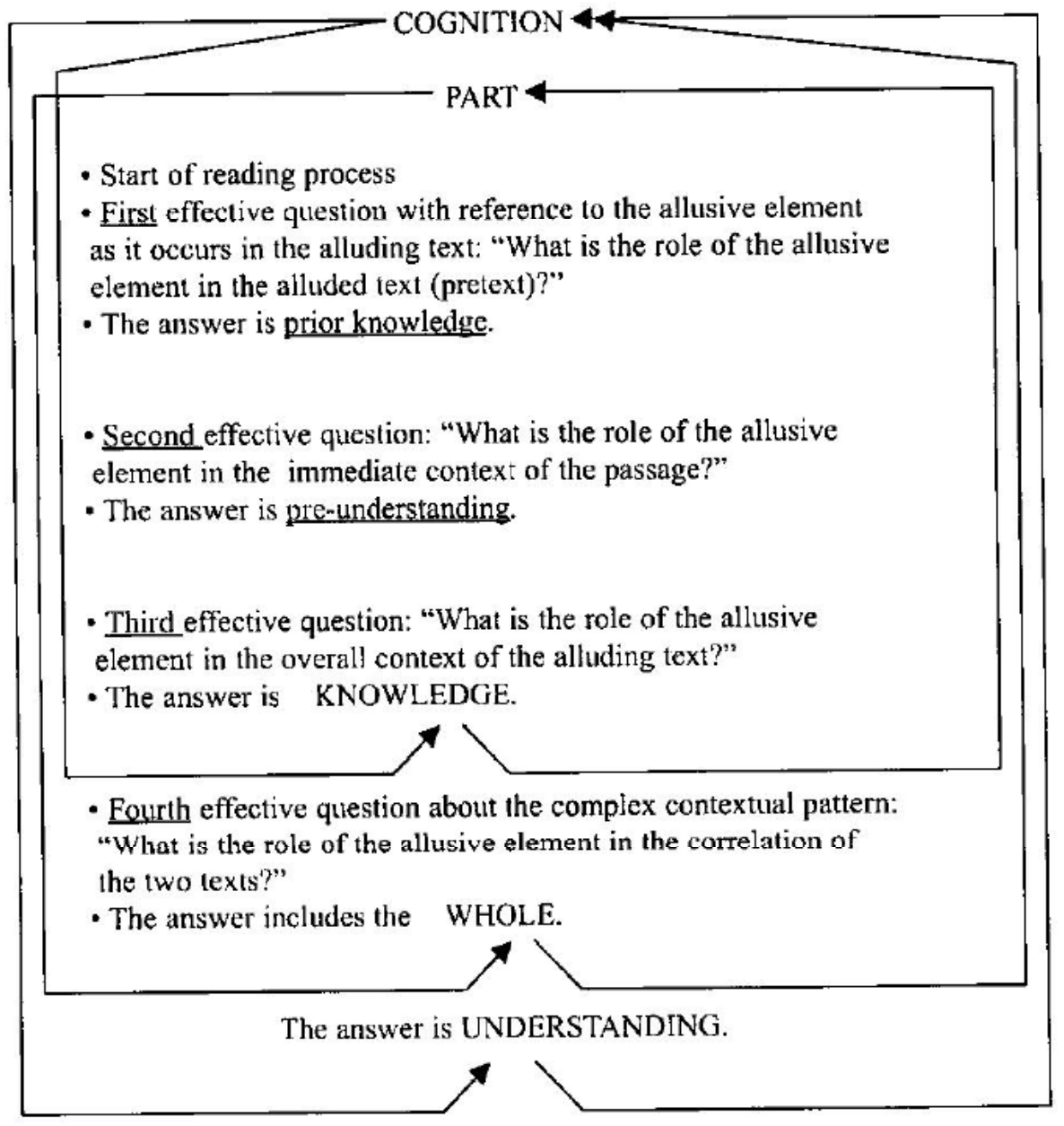

Apart from displaying the hierarchy of questions and consequently, the structure of meaning, this paradigm makes it possible to observe an analogy between literary alkusion and a riddle. As a literary form, a riddle incorporates a direct question by answering which the reader figures out the meaning. In the interpretation of literary allusion too, the structure of question reveals the connection between knowledge and meaning, with the only difference that the reader becomes conscious of and formulates the question himself: 'What extension of meaning does allusion enable that is not readily 'deciphered' within the limits of the text? What is its aesthetic value?'

The next two characteristic features central to literary allusion are self-evident. The aesthetic impact is directly connected with the stylistic value of this textual (and intertextual) phenomenon - its being a trope. The evaluative aspect reflects the reader's appreciation and combines both the aesthetic and the cognitive. 
At this point it seems appropriate to consider the potential of allusion-riddle by the example of a Jamesian handling of the well-known poetic image of a romanlic maiden. In "Guest's Confession" the narrator contemplates about his relations with Laura Guest:

In so far as I was serious, Miss Guest frankly offered to accept me as a firiend, and langhingly infimated, indeed, that with a little matronly tuition of her dispensing. I might put myself into condition to please some simple maiden in her flower.

(Ch. IV, p. 700)

The narrator, David Musgrave has not yet won Laura's love although he is 'madlv in love' himself. Despite the subtle ironical tonality of the passage (and the story on the whole loo), the metaphorical characterization of Laura Guest as a simple maiden in her flower still sounds as a poetic generalization, the poetic line having an iambic rhythnic pattern made up of alternately arranged unstressed and stressed syllables. I lowever, this seemingly satisfactory interpretation at the level of the passage may be modified to open up a new perspective of interpretation and characterization when the overall contexis of both works are put side by side.

It needs to be emphasized that in the antithetical characterization of Lady Clara Vere de Vere, A simple maiden in her flower/L worth a handred coats of arms sounds as a counterpoise to her vanity, pride and prime. And although in Tennyson's poem it is brief (2 lines) against the 9 verses disclosing Lady Clara Vere de Vere's exaggerated sense of superiority, this archetypal image of purity is indicative of the author's choice of true values.

Applied to one of the Jamesian characters, Tennyson's metaphor resonates in the responsive reader's consciousness. And because it has the power of a counterbalance in the antithetical characterization, the reader might seek to observe a collision of moral values in the Jamesian context. In other words, if a simple maiden in her flower is the Jamesian choice too, then it is likely that the author should provide another character to whom Laura is opposed, which means that by directly characterizing Laura Guest as $u$ simple maiden in her flower, the author indirectly characterizes another one too if he preserves the antithetical opposition. To claim this, as well as the possibility of any stylistic resounding of the Tennysonian metaphor, we need to observe grounds for moral as well as aesthetic opposition. Both can be found in the story.

The character that may be viewed as Laura Guest's opponent in James's story is Mrs. Beck. She is portrayed as one who 'found herself saddled in our prosv modern world with this absurdly perpetual prime'. In another part we read the ironical description of her morality.

Mrs. Beck's morality was not Arcadian; or if it was, it was of a shepherdess with a keen cye to the state of the wool and the mutton market, and a lively perception of the possible advantages of judicious partnership. 
The parallels between Lady Vere de Vere with her sense of superiority and selfconceit (Your pride is yet no mate for mine, I Too prond to care fiom whence I came), and Mrs. Beck with her vanity (absurdly perpetual prime) and prudence even in her emotions (judicions porfnership) are obvious. Certainly, James' attilude is ironical, and I could say, just as ironical as Tennyson's is contemptuous.

As has been mentioned earlier, to speak of indirect characterization, we need to observe aesthetic grounds too. While Laura Guest is portrayed through the allusive expression a simple maiden in her flower: about Mrs. Beck we read:

Cranford had never beheld so finished a piece of ladyhood, it pleased and puzzled him and quickened his honest grin very much as a renarkably neat mechanical tov might have done. Plain people who have lived close to frank nature often think more of a fine crisp muslin rose than of a group of dewy petals of garden growth. Before ten dans were past, he had begun to fumble tenderly with the stem of this unfading flower.

In both cases the analogy with a flower underlies the two images. However, in the second case it arouses neither appreciation: moral or aesthetic, nor poetic associations in the reader, but points to the writer's irony - Crawford's is an unfading flower: if a mzsslin rose. The moral conflict between sincerity and purity on the one and, and conceit and vanity on the other, is presented through the aesthetic opposition between the natural beauty of a group of dewy petats of garden growth and the artificial (or fake) attraction of a fine crisp muslin rose. Therefore, it seems possible to claim that by preserving Tennyson's method of contrasting, James provides for another interpretive possibility namely, that there is antonomasia hidden in the characterization. If Laura Guest is the simple maiden in her flower, then Mrs. Beck is a Lady Clara Vere de Vere. Anyway, the antonomasia may as well be considered overt: Mrs. Beck's name is Clara?.

Playing the game of allusion-riddle by answering the self-formulated puzzlequestion(s), the reader indulges in the process, overcoming the tension of possible misinterpretation, gaining more confidence when each next interpretive step confirms the validity of the previous and discovering something new although that very "new" may be such, provided it is based on prior knowledge. The allusive metaphor a simple maiden in her flower is illustrative of that.

Another observation seems appropriate with reference to prior knowledge and its modification in the interpretive space. Once the complex contextual structure has formed in the reader's horizon of understanding, the Tennysonian phrase becomes representative of the Jamesian context too. And we could presume that even when reading the poem alone, the reader will associate the poetic image - the prototype - with James' model of a simple maiden in her flower.

It is most natural to think that the joumeys that readers make from context to context, formulating questions and answering them, should vary. Nevertheless, despite the unique nature of every such experience, the relations in which literary allusion exists are 
objective, and every reader reflecting on them becomes conscious of the route, the route which is one and which leads to understanding.

\section{References and Notes:}

1. J. Pucci connects the ludic aspect of allusion to its interpretation, focusing on the role of a full-knowing reader.

Pucci Joseph. The Full-Knowing Reader: Allusion and the Power of the Reader in the Western Literary Tradition. Yale Univ. Press, USA, 1998.

Another scholar, C. Perri, observes the analogy between alluding and joking, proceeding from the Freudian conception of joking, and emphasizing the 'playful' use of language, in which case the reader's pleasure is that of rediscovering something known.

Perri Carmella. On Alluding // Poetics 7. North-Holland Publ. Co, 1978, p. 30.

2. Гадамер Г.Г. Истина и метод (Основы философской герменевтики). "Прогресс", Москва, 1988, р. 360.

3. Schaar Claes, Linear Sequence, Spatial Structure, Complex Sign, and Vertical Context System // Poetics 7. North-Holland Publ. Co, 1978, p. 382.

4. C. Perri characterizes allusion as 'a link between texts' (Perri, 1978:289).

5. Хейзинга Йохан, Нomo Ludens (Человек играющий). Эксмо-пресс, Москва, 2001, p. 54.

6. The terms understanding and interpretation are conceived as interchangeable here, proceeding from the argument that in the meaning produced by the reader of allusion, the creative component is significant, and so whether the reader arrives at understanding through interpretation, or interpretation results from understanding, is trivial if not disputable.

7. Interestingly, a simple maiden in her flower as a moral and aesthetic generalization occurs in another Jamesian story, Eugene Pickering. Here too, the method of contrasting is used: the two opponents are Isabel Verver and Madaine Blumenthal.

\section{Sources of Data:}

1. Henry James. Guest's Confession // Complete Stories. 1864-1874. The Library of America, USA, 1999.

2. Alfred Tennyson. Lady Clara Vere de Vere // Alfred Lord Tennyson's Poetry. http:/home.att.net/ Tennyson Poetry/cv.htm 


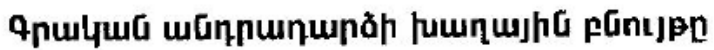

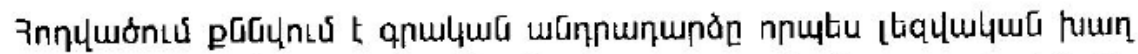

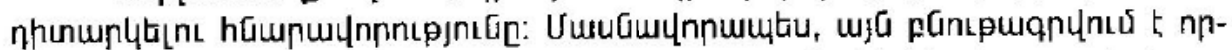

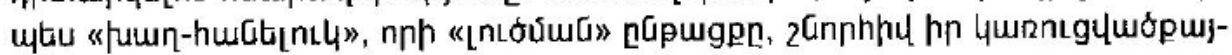

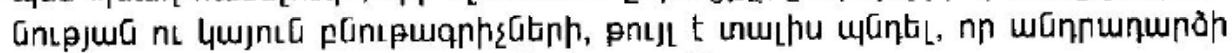

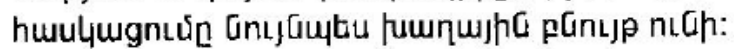

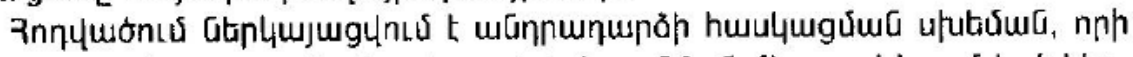

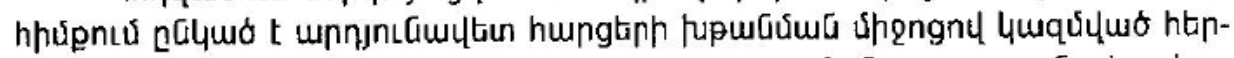

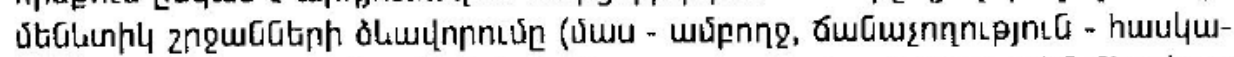

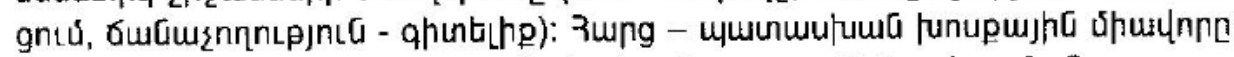

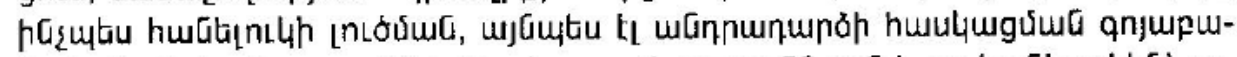

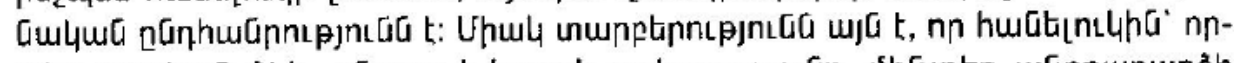

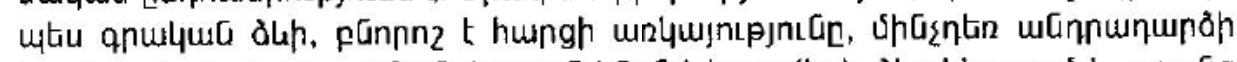

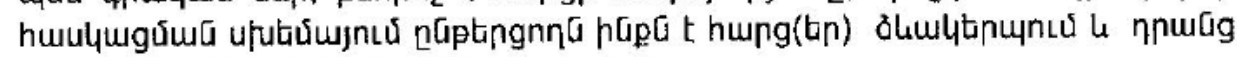

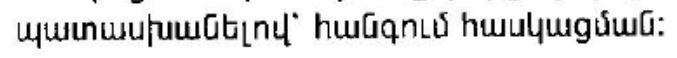

